\title{
Coulisses
}

Revue de théâtre

6 | Printemps 1992

Varia

\section{Rencontre avec les élèves-comédiens}

\section{(2) OpenEdition}

1 Journals

Édition électronique

URL : http://journals.openedition.org/coulisses/1843

DOI : $10.4000 /$ coulisses. 1843

ISSN : 2546-9460

Éditeur

Presses universitaires de Franche-Comté

\section{Édition imprimée}

Date de publication : 1 juin 1992

ISSN : 1150-594X

Référence électronique

«Rencontre avec les élèves-comédiens », Coulisses [En ligne], 6 | Printemps 1992, mis en ligne le 15 mars 2019, consulté le 22 octobre 2019. URL : http://journals.openedition.org/coulisses/1843 ; DOI : $10.4000 /$ coulisses. 1843

Ce document a été généré automatiquement le 22 octobre 2019

Coulisses 


\section{Rencontre avec les élèves- comédiens}

Coulisses a rencontré six des comédiens en formation qui ont participé à la représentation de La Divine Comédie. Le premier point de discussion a été l'opacité du texte. La plupart des élèves n'avaient jamais lu l'œuvre de Dante et la confrontation avec le texte ne fut pas facile.

\section{Les résistances du texte}

«Le texte nous a été imposé. Ce qui nous a gênés et qui a été le plus difficile, ce sont les problèmes de compréhension. La Divine Comédie est un morceau énorme, un texte médiéval qu'il faut resituer dans son époque. On n'avait pas beaucoup d'appui sur le texte. Ce qui nous a manqué, c'est un réel travail d'analyse. »

«On a mis énormément de temps à comprendre vraiment tout ce que signifiait le texte. A certains moments, il fallait qu'on nous explique mot à mot ce que cela voulait dire. C'est un texte qui nous a résisté. Le sens global, bien sûr, on l'a tous compris mais la signification profonde, le sens de certains passages, nous ont souvent échappé. »

"Je ne sais pas si Patrick Melior savait que ce serait aussi loin de nous. Il était conscient que c'est quelque chose qui fonctionne à retardement, aussi bien pour le spectateur que pour nous. A certains moments, je disais des phrases du texte et tout à coup je comprenais, alors que cela faisait des jours, des semaines que j'étais sur ce passage. »

\section{Sur l'écriture de Dante}

«L'écriture de Dante est très riche et en même temps très lourde. C'est différent du théâtre contemporain où le texte a une espèce de légèreté, quelque chose de quotidien. Là, on ne peut pas s'approprier le texte en une fois. » 
«Ce n'est pas un texte facile à mettre en bouche... Où placer les respirations? Comment attaquer les phrases? Bien les finir? ...»

\section{Le travail corporel}

«On a travaillé avec Martine Fioux. Tous les chœurs sont issus d'improvisations et ça a été un travail très physique non seulement sur le plan individuel mais aussi collectivement car il y a un rythme d'ensemble important. »

«Ce qui était bien dans cette session, c'est qu'on a fait un travail diversifié : on a pris des cours de maquillage, de chant, de danse. On s'est beaucoup centré sur le corps, la rythmique collective. »

\section{Après la représentation}

« Le public a surtout aimé la première partie, l'Enfer, car il y avait un travail visuel, corporel. Dans le Paradis, le texte domine, il y a peu de jeu d'acteur et j'ai l'impression que le public a décroché, s'est plutôt ennuyé. »

«Les gens ont trouvé qu'il y avait beaucoup de présence de la part de chacun, une unité dans le jeu, des petits aux grands rôles. »

« Le travail de chœur était bien, je crois. Par contre, pour la voix, la diction, c'était moins bien. On a encore beaucoup à apprendre... J'aimerais bien, l'an prochain, qu'on fasse plus de travail vocal. »

La Divine Comédie 

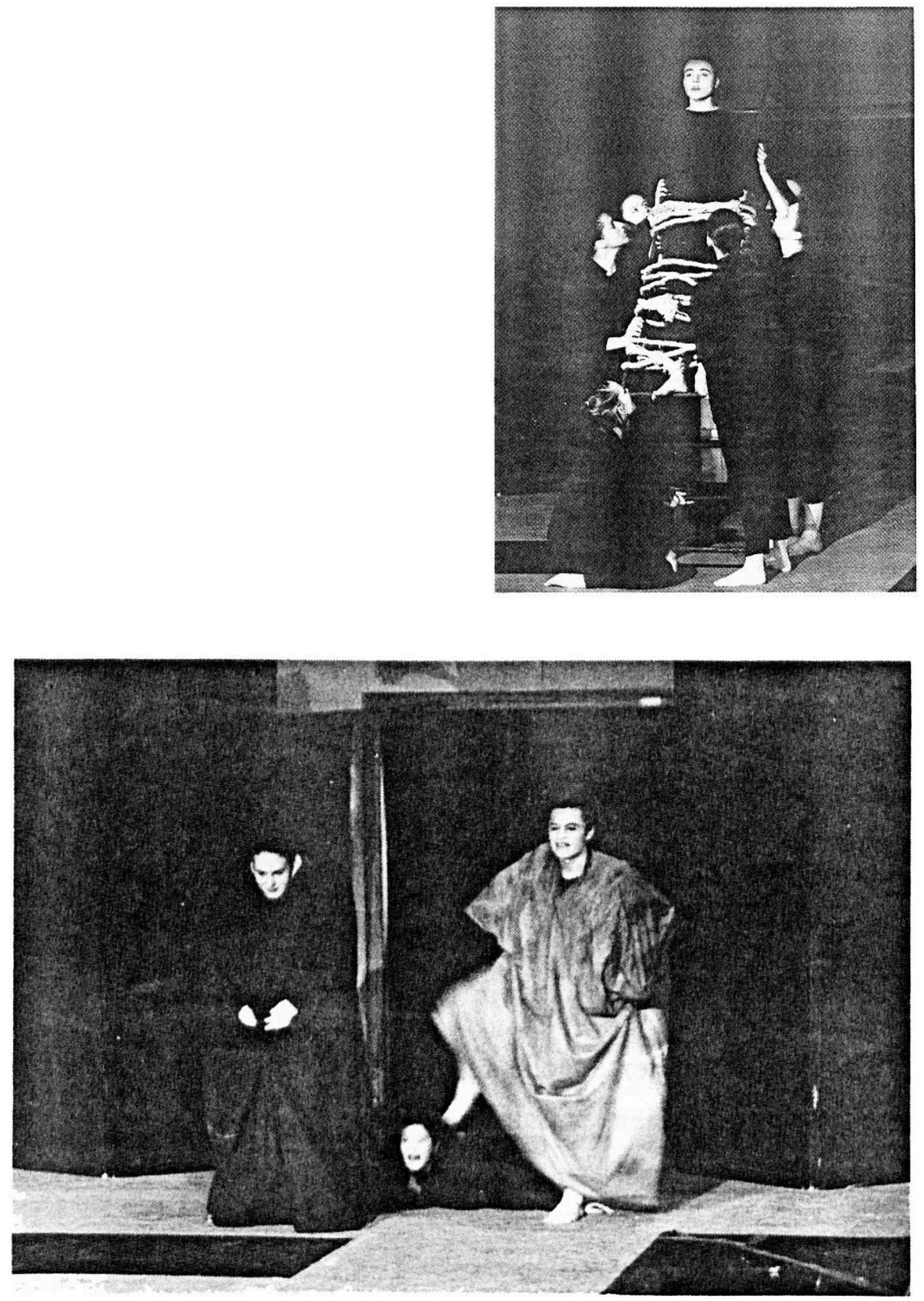

Photo Marc Sergent 